\title{
A non-linear Keynesian Goodwin-type endogenous model of the cycle: Bayesian evidence for the USA
}

LSE Research Online URL for this paper: http://eprints.Ise.ac.uk/100229/

Version: Accepted Version

\section{Article:}

Mariolis, Theodore, Konstantakis, Konstantinos N., Michaelides, Panayotis G. and Tsionas, Efthymios G. (2019) A non-linear Keynesian Goodwin-type endogenous model of the cycle: Bayesian evidence for the USA. Studies in Nonlinear Dynamics and Econometrics, 23 (1). ISSN 1081-1826

https://doi.org/10.1515/snde-2016-0137

\section{Reuse}

Items deposited in LSE Research Online are protected by copyright, with all rights reserved unless indicated otherwise. They may be downloaded and/or printed for private study, or other acts as permitted by national copyright laws. The publisher or other rights holders may allow further reproduction and re-use of the full text version. This is indicated by the licence information on the LSE Research Online record for the item. 


\title{
A non-linear Keynesian Goodwin-type endogenous
}

\author{
model of the cycle: Bayesian evidence for the USA
}

\author{
Theodore Mariolis
}

Panteion University, Greece

\author{
Konstantinos N. Konstantakis \\ National Technical University of Athens, Greece
}

Panayotis G. Michaelides

National Technical University of Athens, Greece

\& Systemic Risk Centre, London School of Economics, United Kingdom

\author{
Efthymios G. Tsionas \\ Athens University of Economics and Business, Greece \\ \& Lancaster University Management School, United Kingdom
}

Contact Author: Panayotis G. Michaelides, Laboratory of Theoretical \& Applied Economics; School of Applied Mathematics \& Physics; National Technical University of Athens, Greece; Heroon Polytechneiou 9, 157.80, Zografou Campus; Tel: 302107721624, fax: +302107721618, email: pmichael@central.ntua.gr. 


\title{
A non-linear Keynesian Goodwin-type endogenous model of the cycle: Bayesian evidence for the USA
}

\begin{abstract}
This paper incorporates the so-called Bhaduri-Marglin accumulation function in Goodwin's original growth cycle model and econometrically estimates the proposed model for the case of the US economy in the time period 1960-2012, using a modern Bayesian sequential Monte Carlo method. Based on our findings, the US economy follows an exhilarationist regime throughout our investigation period with the sole exception of an underconsumption regime for the time period 1974-1978. In general, the results suggest that the proposed approach is an appropriate vehicle for expanding and improving traditional Goodwin-type models.
\end{abstract}

Keywords: Bayesian sequential Monte Carlo methods, Bhaduri-Marglin accumulation function, Goodwin type models, US economy

JEL classification: B51, C11, C62, E32 


\section{Introduction}

Although a number of mathematically elegant models that are based on Goodwin's (1967) class struggle approach have emerged, their empirical estimation does not, however, always end up in success.

As we know, Goodwin's original growth cycle model, which constitutes an equivalent of the Lotka-Volterra predator-prey system, is 'conservative' and, therefore, 'structurally unstable', i.e. sensitive to perturbations in its functional structure. ${ }^{1}$ In fact, based on Tavani and Zamparelli's (2015, p. 209) apposite formulation, all models that belong to the Goodwin class are based on accumulation which is driven by savings out of profits: "The byproduct of investment in new capital goods by asset-owners (capitalists, in typical two-class modelling jargon) is an increase in firms' demand for labour, which in turn puts upward pressure on real wages relative to labour productivity, thus increasing the share of wages in output. Now that workers have gained distributional ground, profitability suffers, and accumulation slows down. Employment will recede, and real wages will fall relative to labour productivity. At this point, profitability is restored, and accumulation can pick up again". Of course, this instability is also inherent to all "pseudo-Goodwin models", and a key example comes from the model of Stockhammer and Michell (2017), according to which the wage-led demand regime in conjunction with a "reserve army" distribution function does constitute a force for long-run instability of the system (Stockhammer and Michell, 2017, p. 120).

However, this inherent instability of the Goodwin class models could be eliminated, according to Tavani and Zamaprelli (2015), with the introduction of a feedback from income distribution to labour productivity which, in turn, changes the dynamics of the interaction between employment and distribution, by making the steady state equilibrium locally stable. This transformation of the steady state, from structurally unstable to locally stable, is crucially dependent on the induced technical change which allows the capitalists to break the bargaining positions of workers' demands towards capital accumulation, a fact that makes the growth cycle disappear in the long run (Shah and Desai, 1981; Tavani and Zamparelli, 2017).

\footnotetext{
${ }^{1}$ However, the absence of inherent 'structural stability' in Goodwin's model is not a reason for rejecting it a priori (see, e.g. Vercelli, 1984; Sportelli, 1995; Veneziani and Mohun, 2006).
} 
Nonetheless, Goodwin's class models remain relatively appealing to researchers due to their simplicity. In fact, recent attempts in the literature to endogenize the technical change by Zamparelli (2015), and Tavani and Zamparelli (2015), managed to re-establish the positive influence of thrift on the labour share, which characterizes the Goodwin model. In Goodwin-type models, labour productivity growth and the level of capital productivity are exogenous; higher saving requires a shift in income distribution away from profits to reconcile the accumulation of capital with productivity growth. When technical change is endogenous, a higher saving rate permanently increases productivity growth. A rise in the employment ratio is necessary to allow wage growth to catch-up with higher labour productivity; the increase in labour demand produces the increase in the wage share. In both cases, the rise in the labour share is necessary to adjust capital accumulation to the natural growth rate; when the natural growth rate is endogenous, however, the adjustment is more complex and requires the rise in the employment rate.

In this particular strand of the literature, one fundamental note - made first by Kaldor (1961) - is that technological progress increases the productivity of labour inputs but not of capital inputs. In this context, according to Tavani (2013, p. 210), "technical change is biased toward labour. [...] The particular bias of technological progress observed in the data is linked to distributive shares, in that technical change will be directed toward augmenting the productivity of the factor becoming more expensive.". The common findings to the whole literature of models, which according to Tavani (2012) feature an exogenously determined wage and an underlying fixed proportions economy operating at full capacity, are that "induced innovation bias produces a long-run pattern of technical change that is Harrod-neutral (purely labor augmenting) and endogenously determines constant factor shares in equilibrium, thus not only matching, but also explaining, the basic Kaldor (1961) facts of economic growth. At the same time, induced bias acts toward 'stabilizing' Goodwin's closed orbits, eventually determining convergence of the dynamics to the long-run equilibrium of the economy" (Tavani, 2013, p. 210). In such models, the speed of convergence is slower than what implied by induced bias in technological change. ${ }^{2}$

On the other hand, several scholars have argued that Goodwin's (1967) approach neglects altogether any effective demand issues, and this has been generally

\footnotetext{
${ }^{2}$ See, e.g. Shah and Desai (1981); van der Ploeg (1987); Foley (2003); Julius (2005); Rodousakis, (2014).
} 
recognized as a fundamental weakness of the model. ${ }^{3}$ In fact, Marglin and Bhaduri (1988) have shown, by means of a static (post-)Keynesian model, that income redistribution between profits and wages has ambiguous effects on the equilibrium rates of capacity utilization, profits and accumulation (see also Bhaduri and Marglin (1990), and Kurz (1990)). Within that model, (i) there is an independent Kaleckian investment (or accumulation) function; ${ }^{4}$ (ii) commodity market is in equilibrium; and (iii) the share of profits in total income (or, equivalently, the real wage rate) is treated as an exogenous variable.

For empirical estimation purposes, the present paper focuses on the underutilization of productive capacity as caused essentially by an insufficient effective demand. ${ }^{5}$ More specifically, this paper: (i) incorporates the Bhaduri-Marglin accumulation function in Goodwin's (1967) model $^{6}$ and briefly explores the dynamics of the extended model $;^{7}$ and (ii) econometrically estimates it for the case of the US economy in the time period 1960-2012, using structural breaks and a modern Bayesian sequential Monte Carlo method, which has considerable advantages over the relevant classical methods. The said incorporation implies that the rate of change of labour employment is (also) determined by the rate of change of capacity utilization, and this connection may finally destroy the system's conservativity (consider, for instance, Lorenz, 1989, p. 61).

The remainder of the paper is structured as follows: Section 2 presents and explores the theoretical model. Section 3 constructs the Bayesian model. Section 4 brings in the empirical evidence. Section 5 discusses the findings. Finally, Section 6 concludes.

\footnotetext{
${ }^{3}$ See the subsequent contributions by Goodwin (1986), and Goodwin and Punzo (1987, ch. 4).

${ }^{4}$ For a recent, critical investigation, both theoretical and empirical, of the Kaleckian accumulation function(s), see Skott (2012).

${ }^{5}$ It is worth noticing that, as argued by Kurz (1994), the endogenous view of the actual rate of capacity utilization is also fully compatible with the growth models constructed by postKeynesians in the Kaleckian tradition (Rowthorn (1981); Amadeo (1986); Dutt (1990); Lavoie, (1995)).

${ }^{6}$ For this line of research, see, e.g. Canry (2005), Barbosa-Filho and Taylor (2006), Flaschel et al. (2009), Tavani et al. (2011), Flaschel and Luchtenberg (2012, ch. 4), Nikiforos and Foley (2012), Sasaki (2013), Kiefer and Rada (2015), and von Arnim and Barrales (2015).

${ }^{7}$ For a detailed exploration of this extended model, which also allows for heterogeneous capital commodities, see Mariolis (2013).
} 


\section{The Theoretical Model}

The theoretical model is presented in two successive stages. The first stage zeroes in on the static 'core' of the model and deals with the relevant comparative static properties. The second one formulates and deals with its complete, dynamic version (dynamization).

\subsection{The static core}

\subsubsection{Assumptions and relations}

Consider a linear, closed, one-commodity and excess capital capacity economy without capital depreciation, inflation and public sector. Competitive conditions are taken to be close to free competition, while homogeneous labour is the only primary input and in perfectly elastic supply. Furthermore, assume that:

(i). Workers are employed in proportion to the level of production, i.e. there is no 'overhead' labour. Thus, $L=\pi_{L}^{-1} Y$, where $L$ denotes the volume of employment, $\pi_{L}$ the technologically fixed labour productivity, and $Y$ the actual output.

(ii). Actual output is distributed between profits and wages. Wages are paid at the end of the production period and there are no savings out of this income, while a given and constant fraction of profits is saved. That is, $S \equiv s P$, where $S$ denotes total savings, $s, 0<s \leq 1$, the savings ratio, and $P, 0 \leq P \leq Y$, the profits.

(iii). The rate of capacity utilization, $u$, is defined as the ratio of actual output to potential output, $\tilde{Y}$, where the latter is taken to be proportional to the capital stock in existence, $K$. That is, $u \equiv Y \tilde{Y}^{-1}$ and $\tilde{Y}=\pi_{K} K$, where $0<u \leq 1$ and $\pi_{K}$ denotes the technologically fixed capital productivity.

(iv). The desired rate of capital accumulation, $g$, is a strictly increasing function of both the rate of capacity utilization and the share of profits in total income, $h \equiv P Y^{-1}$. (v). Goods market is in equilibrium and, moreover, the responsiveness of savings to changes in the rate of capacity utilization exceeds that of investment and, therefore, the goods market equilibrium is stable ('Keynesian stability condition'; see Bhaduri (2008)). 
On the basis of these assumptions, we can write the following relations: ${ }^{8}$

$$
\begin{aligned}
& r \equiv P K^{-1}=\left(P Y^{-1}\right)\left(Y \tilde{Y}^{-1}\right)\left(\tilde{Y} K^{-1}\right)=h u \pi_{K} \\
& w=\pi_{L}(1-h) \\
& \sigma \equiv S K^{-1}=s P K^{-1}=s h u \pi_{K} \\
& g=g(u, h), g_{u}>0, g_{h}>0 \\
& \sigma=g \\
& \sigma_{u}-g_{u}>0 \text { or } s h \pi_{K}>g_{u}
\end{aligned}
$$

where $r$ denotes the profit rate, $w$ the real wage rate, and $\sigma$ the savings-capital stock ratio. Equations (1) and (2) give the proximate determinants of the income distribution variables. Equation (3) gives the proximate determinants of the savingscapital stock ratio. Equation (4) introduces the accumulation function. Finally, equation (5) defines the goods market equilibrium, and relation (6) gives the Keynesian stability condition for this market. It is worth noticing that the real wage rate or, equivalently, the profit share is exogenously given, while the capacity utilization and capital accumulation (or growth) and profit rates are endogenously determined.

\subsubsection{Comparative static}

Using the 'normalized profit rate', $\rho \equiv r u^{-1}$, equations (1) and (2) define a linear ' $\rho-w$ curve (or frontier)', i.e. $\rho=\pi_{K}\left(1-\pi_{L}^{-1} w\right)$, the elasticity, $e_{1}$, of which equals the negative of the wage-profit ratio, i.e.

\footnotetext{
${ }^{8}$ The first derivative of a function $y=y\left(x_{1}, x_{2}\right)$ with respect to the variable $x_{j}$ is denoted by $y_{x_{j}}$.
} 


$$
e_{1}=\rho_{w}\left(w \rho^{-1}\right)=-\pi_{L}^{-1} w\left(1-\pi_{L}^{-1} w\right)^{-1}=-(1-h) h^{-1}
$$

Equations (3), (4) and (5) define an implicit relation between the profit share and the rate of capacity utilization, $u=u(h)$, or ' $I S$ - curve' (non-Hicksian), i.e.

$$
\operatorname{shu} \pi_{K}=g(u, h)
$$

the elasticity, $e_{2}$, of which is given by

$$
e_{2}=\left(g_{h}-s u(h) \pi_{K}\right)\left(s h \pi_{K}-g_{u}\right)^{-1} h(u(h))^{-1}
$$

Since the term $s h \pi_{K}-g_{u}$ is positive (condition (6)), $e_{2}>0$ iff $g_{h}>s u(h) \pi_{K}$, i.e. the responsiveness of investment to changes in $h$ exceeds that of savings.

Finally, differentiation of $r=h u(h) \pi_{K}$ (see equation (1)) with respect to $h$ gives

$$
r_{h}=\left(1+e_{2}\right) u(h) \pi_{K}
$$

from which it follows that an elastic, negatively sloped $I S$ - curve necessarily implies that $r_{h}<0$.

It then follows that the system is able to generate three alternative sets of steady-state equilibria (according to Kurz's, 1990, pp. 222-226, terminology):

(i) A "regime of overaccumulation", characterised by $u_{h}<0$ and $r_{h}>0$, prevails when: $u(h) g_{u}<h g_{h}<\operatorname{sh} u(h) \pi_{K}$.

(ii) A "regime of underconsumption", characterised by $u_{h}<0$ and $r_{h}<0$, prevails when: $h g_{h}<u(h) g_{u}$. In other words, an increase in the real wage rate implies higher profit and growth rates because the positive effect of demand is greater than the negative effect of higher costs ('paradox of costs').

(iii). A "Keynesian regime", characterised by $u_{h}>0$ and $r_{h}>0$, prevails when: $s u(h) \pi_{K}<g_{h}$. 
Bhaduri and Marglin (1990) refer to both the overaccumulation and underconsumption regimes as "stagnationist (or wage-led) regimes without or, respectively, with cooperation between labour and capital". On the other hand, they refer to the Keynesian regime as "exhilarationist (or profit-led) regime", and point out that it involves cooperation between labour and capital iff "a given increase in the profit share stimulates the level of demand and capacity utilisation sufficiently to increase aggregate employment and the wage bill' (p. 384), i.e. iff $(1-h) u$ increases with increasing $h$ or, equivalently, $e_{2} e_{1}<-1$.

\subsection{Dynamization}

\subsubsection{Additional assumptions and motion equations}

Now, following Goodwin (1967), also assume that: ${ }^{9}$

(i). Labour force, $N$, grows at the exogenously given steady rate $n$, i.e. ${ }^{10}$

$$
\hat{N}=n
$$

Steady-state growth at full employment (Harrod-Domar-Kaldor growth path) requires that the 'natural' growth rate, $n$, must be less than the actual rate of capital accumulation corresponding to the maximum feasible value of the profit share, $h=1$, and to any actual value of the capacity utilization rate, $u=\tilde{u}$, i.e.

$$
n<s_{P} \tilde{u} \pi_{K}
$$

(see equation (3)). ${ }^{11}$

\footnotetext{
${ }^{9}$ However, we would like to ignore the possible technical change factors since "the choice of technique problem cannot generally be considered to be decided in terms of the technical conditions of production alone: the degree of capacity utilization matters too. The latter, however, reflects a multiplicity of influences, such as the state of income distribution and savings and investment behavior [...]. In particular, there is the possibility that, assessed in terms of the degree of utilization associated with the existing technique, a new technique proves superior, while in terms of its own characteristic steady-state degree of utilization it turns out to be inferior" (Kurz, 1990, pp. 232-233).

${ }^{10} \mathrm{~A}$ 'dot' over a variable denotes the time derivative of that variable, while a 'hat' denotes the logarithmic derivative with respect to time.

${ }^{11}$ This formulation is inherently different to the one in Zamparelli (2015), who assumes no population growth (and $u=1$ ). Meanwhile, it shares some common features with the work of Tavani (2012) - despite assuming that $u=1$ - whose model: "evolves so as to achieve a
} 
(ii). The real wage rate rises in the neighbourhood of full employment ('real wage Phillips curve'), i.e.

$$
\hat{w}=\gamma E-\delta
$$

where $E \equiv L N^{-1}$ denotes the employment rate, and $\gamma, \delta$ are positive constants.

Equations (2) and (7) imply that $\hat{w}=\hat{h} e_{1}^{-1}$ or, solving for $\hat{h}$ and invoking equation (11),

$$
\dot{h}=e_{1}(\gamma E-\delta) h
$$

Since $L=\pi_{\mathrm{L}}^{-1} u \pi_{K} K$ and $\sigma=\hat{K}$, it follows that $\hat{L}=\hat{u}+\sigma$ or, recalling equations (3) and (8),

$$
\hat{L}=e_{2} \hat{h}+\operatorname{sh} u(h) \pi_{K}
$$

or, recalling equation (12),

$$
\hat{L}=e_{2} e_{1}(\gamma E-\delta)+\operatorname{sh} u(h) \pi_{K}
$$

Finally, substituting equations (10) and (13) in $\hat{E}=\hat{L}-\hat{N}$ yields

$$
\dot{E}=\left[e_{2} e_{1}(\gamma E-\delta)+\operatorname{shu}(h) \pi_{K}-n\right] E
$$

Harrod-neutral path of technical progress, and a constant employment rate. [...] [E]quilibrium unemployment is not 'natural', in the sense that its role is not to prevent an accelerating inflation. Instead, in the spirit of Goodwin (1967), the role of equilibrium unemployment is to put the class-conflict between capital and labour to rest" (Tavani 2012, p. 124). 


\subsubsection{Stability}

Consequently, the model reduces to the non-linear system of equations (12) and (14), which has two equilibria with $\dot{h}=\dot{E}=0$, namely

$$
h^{*}=1, E^{*}=0
$$

And

$$
h^{* *}=n\left(s u\left(h^{* *}\right) \pi_{K}\right)^{-1}, E^{* *}=\delta \gamma^{-1}
$$

where the latter is economically meaningful $\left(0<h^{* *}, E^{* *}<1\right)$ when

$$
n<s u\left(h^{* *}\right) \pi_{K} \text { and } \delta<\gamma
$$

To relations (15a-b) there corresponds a unique value for $\sigma$, i.e. $\sigma=n$, and may correspond, when $e_{2}^{* *}<0$, more than one economically meaningful value for $h$ and, therefore, for $u$ and $w .^{12}$

The relevant Jacobian matrix, $\mathbf{J} \equiv\left[J_{i j}\right]$, is (take into account equation (9))

$$
\begin{aligned}
& J_{11} \equiv \dot{h}_{h}=(\gamma E-\delta) \\
& J_{12} \equiv \dot{h}_{E}=-(1-h) \gamma \\
& J_{21} \equiv \dot{E}_{h}=\left[\left(e_{2 h} e_{1}+e_{2} h^{-2}\right)(\gamma E-\delta)+s\left(1+e_{2}\right) u(h) \pi_{K}\right] E \\
& J_{22} \equiv \dot{E}_{E}=e_{2} e_{1}(2 \gamma E-\delta)+\operatorname{shu}(h) \pi_{K}-n
\end{aligned}
$$

\footnotetext{
${ }^{12}$ Consider, for instance, the case of a linear accumulation function, which necessarily implies
} that $e_{2}<0$. 
At the trivial fixed point, $\left(h^{*}, E^{*}\right), e_{1}^{*}=0$ and $\mathbf{J}^{*}$ is diagonal, with $J_{11}^{*}<0$ and $J_{22}^{*}>0$ (take into account relation (10a)); therefore, it is a saddle point, precisely like in Goodwin's (1967) model. Next, consider the non-trivial fixed point(s), $\left(h^{* *}, E^{* *}\right)$. Then $J_{11}^{* *}=0, J_{12}^{* *}<0$, and there are the following cases:

(i). When $e_{2}^{* *}>0$, it follows that $\operatorname{Tr} \mathbf{J}^{* *}<0$ and Det $\mathbf{J}^{* *}>0$ : locally stable.

(ii). When $e_{2}^{* *}=0$, it follows that $\operatorname{Tr} \mathbf{J}^{* *}=0$ and Det $\mathbf{J}^{* *}>0$ (like in Goodwin's (1967), model): centre. Hence, $\left(h^{* *}, E^{* *}\right)$ is either a focus (stable or unstable) or a centre for the original system (depending on the precise form of $u(h)$; see, e.g. Andronov et al. (1987, pp. 278-280)).

(iii). When $-1<e_{2}^{* *}<0$, it follows that $\operatorname{Tr} \mathbf{J}^{* *}>0$ and $\operatorname{Det} \mathbf{J}^{* *}>0$ : unstable.

(iv). When $e_{2}^{* *}=-1$, it follows that $\operatorname{Tr} \mathbf{J}^{* *}>0$ and $\operatorname{Det} \mathbf{J}^{* *}=0\left(J_{21}^{* *}=0\right)$ : unstable.

(v). When $e_{2}^{* *}<-1$, it follows that $\operatorname{Tr} \mathbf{J}^{* *}>0$ and Det $\mathbf{J}^{* *}<0$ : saddle point. ${ }^{13}$

It is then concluded that the local dynamic behaviour of the system depends on the elasticity of the $I S$ - curve, which, in its turn, depends on the form of the accumulation function. This elasticity determines the effect of a rising profit share on the volume of employment, and may be conceived of as a 'friction coefficient' (also consider Samuelson 1971, pp. 982-983) that alters the conservative dynamics of Goodwin's (1967) system: The equilibrium in the Keynesian regime $\left(e_{2}^{* *}>0\right.$ : positive friction) is locally stable, while that in the overaccumulation regime $\left(-1<e_{2}^{* *}<0\right.$ : negative friction) is unstable. And in the border between these two regimes $\left(e_{2}^{* *}=0\right)$, the possible existence of cyclic paths cannot be excluded. Finally, the equilibrium in the underconsumption regime $\left(e_{2}^{* *}<-1\right)$, where Det $\mathbf{J}^{* *}$ switches from positive to negative, is saddle-path stable. ${ }^{14}$

Summing-up, the wage-led regime corresponds to the case where "a rise in the wage share stimulates economic activity due to the strong response of consumption to a higher wage share, compared to the weaker negative response of investment demand

\footnotetext{
${ }^{13}$ It could be shown that a 'U-shaped' IS - curve (Bhaduri and Marglin, 1990, pp. 392-393) may generate a Hopf bifurcation of periodic solutions (Mariolis, 2013, p. 144).

${ }^{14}$ It is noted that, due to production substitution possibilities, a "constant elasticity of substitution production function' leads to simpler dynamic behaviours: at the non-trivial fixed point(s) the system is locally stable or saddle-path stable (Rodousakis, 2015).
} 
to lower profitability" (Kiefer and Rada, 2015, p. 1336). In contrast, the profit-led regime corresponds to the case where "investment responds strongly to increased profitability implied by a decreasing wage share; sometimes this early stage is known as 'forced saving' consistent with the classical assumption that capitalists save all profits." (Kiefer and Rada, 2015, p. 1337).

Although it is theoretically expected that open economies running large trade deficits tend to be profit-led (see Blecker (1989); von Arnim et al. (2014)), the empirical evidence - so far - provides, however, mixed results. Thus, Blecker (2016, p. 375) argues that: "the positive effects of a higher profit share (or lower labor costs) on investment and net exports are mainly short-run phenomena, while the sensitivity of workers' consumption to their wage income is, if anything, likely to be stronger in the longer term. As a result, holding other factors equal, national economies are more likely to exhibit profit-led (or more weakly wage-led) demand in the short run and more likely to exhibit wage-led (or more strongly wage-led) demand in the longer term".

\section{Econometric Model and Data}

\subsection{The estimable model}

The theoretical model should be confronted with data in order to allow formal statistical estimation of parameters and functions of interest. Thus, in order to transform it into an estimable model, we introduce a linear approximation of the $I S-$ curve, i.e.

$$
u(h)=z h+\theta
$$

where $z$ and $\theta$ are real-valued parameters. Substituting equation (17) in equation (14) yields

$$
\frac{\dot{E}}{E}=e_{2} e_{1} \gamma E+\theta s \pi_{K} h+z s \pi_{K} h^{2}-\left(n+e_{2} e_{1} \delta\right)
$$

For given $E, \frac{\dot{E}}{E}, s \pi_{\kappa} h$ and $s \pi_{\kappa} h^{2}$, based on the economy's aggregate data, the estimation of equation (18) is straightforward. 
This procedure will provide us with direct estimates of $z$ and $\theta$. Also, it will provide us with an estimate of $e_{2} e_{1} \gamma$. Given that $e_{1}=-\frac{(1-\bar{h})}{\bar{h}}$ and $e_{2}=\frac{z \bar{h}}{z \bar{h}+\theta}$, we obtain an estimate of $\gamma$, where, in general, $\bar{x}$ denotes the average value of variable $x$. Similarly, given that $n$ is exogenous, and can be calculated routinely based on the available data, from the estimate of the intercept in (18), we obtain the value of $\delta$, since $e_{1}$ and $e_{2}$ are calculated as above.

This model leads to a single-equation estimate of a relationship between distribution and economic activity that should be interpreted as the joint outcome of the random shocks to distribution and utilization and the inherent dynamic behavior of these variables. See, for instance, Kiefer and Rada (2015, pp. 1338-1339).

\subsection{Bayesian Estimation}

Before proceeding, we introduce the notation $(x) \oplus \sum_{b=1}^{B} a_{b, 1} D_{b}$ where $D_{b}, b=1, \ldots, B$ is a set of $B$ dummies to denote structural breaks. The notation means that the set of dummies, and the set of dummies multiplied by the variables in $x$ are included in the equation.

For example

$$
\begin{aligned}
& \left(\beta_{1} x_{1}+\beta_{2} x_{2}\right) \oplus \sum_{b=1}^{B} a_{b, 1} D_{b}=\beta_{1} x_{1}+\beta_{2} x_{2}+\sum_{b=1}^{B} a_{b, 1}^{(1)} D_{b}+x_{1} \sum_{b=1}^{B} a_{b, 1}^{(2)} D_{b}+ \\
& x_{2} \sum_{b=1}^{B} a_{b, 1}^{(3)} D_{b} .
\end{aligned}
$$

We have the system of equations

$$
\begin{gathered}
\hat{w}=(\gamma E-\delta) \oplus \sum_{b=1}^{B} a_{b, 1} D_{b}+v_{1} \\
\frac{\Delta h}{h}=\left(e_{1} \hat{w}\right) \oplus \sum_{b=1}^{B} a_{b, 2} D_{b}+v_{2} \\
\frac{\Delta E}{E}=\left(e_{2} \frac{\Delta h}{h}+\theta s \pi_{K} h+z s \pi_{K} h^{2}-n\right) \oplus \sum_{b=1}^{B} a_{b, 3} D_{b}+v_{3}
\end{gathered}
$$


where the latter is economically meaningful $\left(0<h^{* *}, E^{* *}<1\right)$, when the relations (15b) are satisfied.

Moreover:

$$
\mathbf{v} \equiv\left(v_{1}, v_{2}, v_{3}\right)^{\prime} \sim N(\mathbf{0}, \boldsymbol{\Sigma})
$$

is a vector error term. Let the parameter vector be

$$
\boldsymbol{\theta} \equiv\left(e_{1}, e_{2}, \gamma, \delta, \theta\right)
$$

The system in (19) is a triangular simultaneous equations system, which is nonlinear in the parameters, and is also subject to the cumbersome restrictions in (15b), which also involve the parameter vector $\boldsymbol{\theta}$. We can write compactly the system in (19) in the following form:

$$
\mathbf{Y}_{t}=\mathbf{X}_{t} \boldsymbol{\alpha}(\boldsymbol{\theta})+\mathbf{v}_{t}, t=1, \ldots, T
$$

where $\mathbf{Y} \equiv\left[\hat{w}, \frac{\Delta h}{h}, \frac{\Delta E}{E}\right], \mathbf{X}$ is the matrix of right-hand-side variables in (19), and $\boldsymbol{\alpha}(\boldsymbol{\theta})$ is the vector of coefficients. The likelihood function is:

$$
\begin{aligned}
& L(\boldsymbol{\theta}, \boldsymbol{\Sigma} ; \mathbf{Y}) \propto|\Sigma|^{-T / 2} \exp \left\{-\frac{1}{2} \sum_{t=1}^{T}\left(\mathbf{Y}_{t}-\mathbf{X}_{t} \mathbf{\alpha}(\boldsymbol{\theta})\right)^{\prime} \boldsymbol{\Sigma}^{-1}\left(\mathbf{Y}_{t}-\mathbf{X}_{t} \mathbf{\alpha}(\boldsymbol{\theta})\right)\right\}= \\
& |\boldsymbol{\Sigma}|^{-T / 2} \exp \left\{-\frac{1}{2} \operatorname{tr} \mathbf{A}(\boldsymbol{\theta}) \boldsymbol{\Sigma}^{-1}\right\}
\end{aligned}
$$

where $\mathbf{A}(\boldsymbol{\theta}) \equiv \sum_{t=1}^{T}\left(\mathbf{Y}_{t}-\mathbf{X}_{t} \mathbf{\alpha}(\boldsymbol{\theta})\right) \cdot\left(\mathbf{Y}_{t}-\mathbf{X}_{t} \mathbf{\alpha}(\boldsymbol{\theta})\right)^{\prime}$

Our prior is in the standard non-informative class

$$
p(\boldsymbol{\theta}, \boldsymbol{\Sigma}) \propto|\boldsymbol{\Sigma}|^{-(M+1) / 2} I(\boldsymbol{\theta} \in \boldsymbol{\Theta})=|\boldsymbol{\Sigma}|^{-2} I(\boldsymbol{\theta} \in \boldsymbol{\Theta})
$$


where $\Theta$ denotes the set of restrictions in (15b), and $\mathrm{I}()$ is the indicator function. Combining the likelihood and the prior, we have the posterior:

$$
p(\boldsymbol{\theta}, \boldsymbol{\Sigma} \mid \mathbf{Y}) \propto|\boldsymbol{\Sigma}|^{-(T+4) / 2} \exp \left\{-\frac{1}{2} \operatorname{tr} \mathbf{A}(\boldsymbol{\theta}) \boldsymbol{\Sigma}^{-1}\right\}
$$

We analyze the posterior in (20) using Markov Chain Monte Carlo techniques and, especially, a Sequential Monte Carlo (SMC) / Particle-Filtering procedure. For further details, see the Technical Appendix.

\subsection{Data}

In order to proceed with formal estimation, data on $h, E, s$ and $\pi_{\kappa}$ are needed. Our investigation starts in 1960 and stops in 2012. The variables used are: Employment and Population in number of persons; Capital, GDP and Labour Cost in 2000 constant prices in millions of US dollars. The data come from OECD's AMECO database. The variable of savings comes from the US Federal Reserve Bank of St. Louis, also in constant 2000 prices in millions of US dollars. The profits are calculated based on the methodology used, among others, in Wolff (2003). In addition, the capital productivity, $\pi_{\kappa}$, is equal to the share of potential output-capital ratio, where the potential output is, typically, obtained as the HP filtered GDP time series.

\section{Empirical Results}

First of all, based on the model selection results of our analysis, we can infer that the linear approximation of the $I S$ - curve (equation (17)) is optimal, based on the values of the Schwarz-Bayes (BIC) and Akaike (AIC) information criteria, respectively. These results fully justify our approximation (Table 0 ).

\section{Please in insert Table 0 around here}

Next, we run the SMC procedure 25,000 times, discarding the first 5,000 to mitigate possible start up effects. We use 10,000 particles per iteration. 
As the number of breaks, $B$, is unknown we assume $B \in\{1,2, \ldots, \bar{B}\}$, where $\bar{B}$ is an upper bound, and we run the SMC procedure for the different values of $B$. The model with $\bar{B}=3$ yielded the best marginal likelihood and, therefore, we proceed conditional on this value. The marginal likelihood is:

$$
M(\mathbf{Y})=\frac{L(\boldsymbol{\theta} ; \mathbf{Y}) p(\boldsymbol{\theta})}{p(\boldsymbol{\theta} \mid \mathbf{Y})}=\int L(\boldsymbol{\theta} ; \mathbf{Y}) p(\boldsymbol{\theta}) d \boldsymbol{\theta}
$$

and provides all prior and data evidence in favor of a given model. Since it is standard output from the SMC procedure, we use it to determine the number of breakpoints and locate them. We use the following procedure:

i) To determine the first breakpoint we estimate all possible models with a breakpoint between 1965 and 2010. We locate it at 1973 with a marginal likelihood equal to -51.43 .

ii) To determine the second breakpoint, we keep the first, and we estimate all possible models with a breakpoint between 1975 and 2010. We locate it at 1978 with a marginal likelihood equal to -59.43 .

iii) To determine the third breakpoint, we keep the first two, and we estimate all possible models with a breakpoint between 1985 and 2010. We locate it at 2006 with a marginal likelihood equal to -60.93 .

iv) To determine the fourth breakpoint, we keep the first three, and we estimate all possible models with a breakpoint between 2008 and 2010. We are unable to locate a new breakpoint as the marginal likelihood is -40.93 , which is much lower compared to case (iii).

v) To mitigate possible errors arising from this sequential procedure we allow for three breakpoints located at those, which we found earlier. We assume that the first breakpoint can be anywhere in $\{1971,1972,1973,1974,1975\}$; the second anywhere in $\{1977,1978,1979,1980,1981\}$; and the third anywhere in $\{2004,2005,2006,2007,2008,2009\}$. This produces $5 * 5 * 6=150$ different 
models which can be estimated ${ }^{15}$, and we compute their marginal likelihood. The highest marginal likelihood was -60.93 , corresponding to (iii), showing that we cannot re-arrange the breakpoints to yield a better model.

Our empirical results, using flat priors over the domain defined by the restrictions that we have, are provided in Table 1.

Please insert Table 1 around here

In Figures 1 to 6, we report marginal posterior densities in the different subperiods. From the marginal posterior densities reported, it is evident that many posteriors are non-normal, especially for $e_{1}, e_{2}, z$ and $\gamma$. This would make asymptotically-based inference somewhat suspect in this application.

Please insert Figures 1-6 around here

Now, from equations (16a) to (16d), using the estimates of the coefficients $\gamma$, $\delta, \theta, z$ computed earlier, and the average values of $E, h, s \pi_{\kappa}$, for each period examined, we obtain the Jacobian matrix $\mathbf{J}$, for each period examined. Table 2 summarizes the regimes and stability results of the estimated models based on the criteria presented earlier (Section 2).

Please insert Table 2 around here

\footnotetext{
${ }^{15}$ Estimation involves a simple loop over alternative breakpoint dates.
} 


\section{Summary and Discussion}

Following the relevant literature regarding the US economy in the time period 19602012, we empirically tested for the existence of outliers using Bayesian inference. According to Dumenil and Levy (2001), in the mid 60's, the profit rate in the US economy changed dramatically, signifying the end of what is now characterized as the Golden Age of US Capitalism, coinciding with a profit squeeze and a rise in savings. Our main finding, i.e. that the first years of the 1960s act as outliers and should be excluded from the analysis, is expected and consistent, in general terms, with the relevant literature arguing that the 1960s is a decade when the first phase of the Golden Age of the US economy ended.

Now, based on economic intuition, we proceeded by testing for the existence of a structural break around the early 1980's, which marks an upward phase in the US profit rate (see, among others, Goldstein (1996), Dumenil and Levy (2001), and Mohun (2009)), followed by the second oil crisis that is said to have ended in the early 1980's. Based on sequential Monte Carlo, we identified two structural breaks that coincided with the first and second oil crises in 1973 and 1978, respectively. Additionally, according to our findings, a third structural break is evident in the data for the year 2006, which in turn could be attributed to the US subprime crisis. As a result, the sub-periods investigated are the time spans: 1960-1973, 1974-1978, 19792006, 2006-2012. Notice that the use of Bayesian estimation allowed as to fully exploit the information derived by the data despite their small length.

The structural breaks detected in our analysis in the early and late 70's could be attributed to the two oil crises that took place in this period. More specifically, the US economy's growth and use of oil and gas energy grew rapidly together from World War II and onwards. This seemingly symbiotic relationship ended when nominal oil prices jumped eight-fold due to the first oil crisis in 1973, triggering the worst US recession since World War II (as well as before the subprime mortgage crisis of December 2007-June 2009). Subsequent recessions have followed every significant, if generally short-term, oil price hike. In this context, the second oil crisis in the late 70's influenced significantly the US economy, changing the energy demand levels and consequently the output growth of the economy. It is worth noticing that the cumulative oil price jump, accounting for both oil crises, correlates with a nine- 
fold increase in natural gas price, a four-fold increase in coal price, a three-fold increase in cost of electricity, and a significant drop in energy demand (Skov, 2004).

Another structural factor that could lie behind the second structural break in the US economy is the tremendous growth in the use of computers in production, in the late 1970's, which Freeman (1987) and others have termed a new 'technoeconomic paradigm,' based on computer-driven information technology. David (1991) referred to 'the paradigmatic shift' from electromechanical automation to information technologies and argued that the shift to information technologies entailed major changes in the organizational structure of companies, and thus the economy as a whole. Of course, this shift towards information technologies was accompanied by a shift of the labour force towards skilled workers that were able to use and exploit the new potentials that would arise from the use of computers (Wolff, 2006). As expected, this shift in the composition of the US labour force, shifted the overall demand of the US economy, as a whole.

Lastly, the structural break detected in 2006 could be attributed to the subprime crisis that hit the US housing market, and transformed to a severe financial crisis that took global dimensions in the period 2007-2009. This crisis led to the implementation of more strict screening procedures from financial institutions, which in turn led to a shift in the aggregate demand of the US economy.

In brief, from the estimation results, we can see that the signs of the estimated coefficients are consistent with the model's stated hypotheses, namely: $\gamma, \delta>0$ such that $\delta<\gamma$ and $e_{1}<0$. Also, the estimated posterior probabilities of all the parameters investigated showed exceptional convergence properties, as can been seen by the various marginal posterior densities presented earlier (Figures 1-6).

As far as the accumulation regimes and stability conditions are concerned, it follows that the US economy, in the period 1960-1973, is characterized by an "exhilarationist" or profit-led regime (also see Bowles and Boyer (1988), and Gordon (1995)), involving “cooperation between capital and labour" (since $e_{2} e_{1}<-1$ ), and seems to be in a stable path. In other words, during the aforementioned period, investment in the US economy responded strongly to increased profitability implied, by a decreasing wage share (see also Kiefer and Rada (2015)). The same picture is in force for the sub-period of 1979-2006 and 2007-2012 (also see Barbosa-Filho and Taylor (2006); Barbosa-Filho (2015); Kiefer and Rada (2015)) just after the second 
oil crisis with the emergence of new technology trends that attracted the majority of investment activity in the USA (Dumenil and Levy, 2001), and of course after the US subprime crisis. Nevertheless, the period 1974-1978 is characterized by an "underconsumption regime" which in turn corresponds, according to Bhaduri and Marglin (1990), to a wage-led regime, meaning that an increase in the real wage rate implies higher profit and growth rates and the economy is saddle-path stable. This could, in turn, be attributed to the stagflation that the US economy faced (see, e.g. Dumenil and Levy (2001)), which was accompanied by the profit squeeze that followed the Golden era of capitalism. Of course, the wage-led regime that the US economy followed during the period 1974-1978 is characterized by a rise in the wage share, which stimulated economic activity due to the strong response of consumption, compared to the weaker negative response of investment demand to lower profitability. In a broader context, our main findings for the US economy as a whole coincide with the relevant literature, according to which the US economy consistently displays 'counter-clockwise' cycles between employment rate and labour share of income, utilization rate and labour share of income as well as utilization rate and employment rate (see Barrales and von Arnim (2017)).

Finally, taking into account the interdependence between national economies over the "second globalization era" (1990s-2010s), it could be added that increasing capital mobility implies a tendency towards the equalization of national profit rates and, therefore, a specific relationship between national wage shares and rates. ${ }^{16}$ In fact, evidence from a panel of thirteen OECD countries (including US) over the period 1970-2012 suggests that, although demand is profit-led, there are long-term declines in both the wage shares and the rates of capacity utilization, which appear to

${ }^{16}$ Consider a two-country (A and B) framework, and abstract, for brevity's sake, from capacity utilizations, taxes and exchange rate changes. Then $r^{\mathrm{A}}=r^{\mathrm{B}}=\tilde{r}$ and equations (1) and (2) imply that $h^{\mathrm{A}}\left(h^{\mathrm{B}}\right)^{-1}=\pi_{K}^{\mathrm{B}}\left(\pi_{K}^{\mathrm{A}}\right)^{-1}$ and

$$
w^{\mathrm{A}}\left(w^{\mathrm{B}}\right)^{-1}=\pi_{L}^{\mathrm{A}}\left(\pi_{L}^{\mathrm{B}}\right)^{-1}\left[1-\left(\pi_{K}^{\mathrm{A}}\right)^{-1} \tilde{r}\right]\left[1-\left(\pi_{K}^{\mathrm{B}}\right)^{-1} \tilde{r}\right]^{-1}
$$

or

$$
w^{\mathrm{A}}\left(w^{\mathrm{B}}\right)^{-1}=\tilde{w} \equiv \lambda\left(\pi_{K}^{\mathrm{A}}-\tilde{r}\right)\left(\pi_{K}^{\mathrm{A}}-\kappa \tilde{r}\right)^{-1} \approx \lambda\left[1+(\kappa-1)\left(\pi_{K}^{\mathrm{A}}\right)^{-1} \tilde{r}\right]
$$

where $\lambda \equiv \pi_{L}^{\mathrm{A}}\left(\pi_{L}^{\mathrm{B}}\right)^{-1}, \kappa \equiv \pi_{K}^{\mathrm{A}}\left(\pi_{K}^{\mathrm{B}}\right)^{-1}$ and $\tilde{r}<\min \left\{\pi_{K}^{\mathrm{A}}, \pi_{K}^{\mathrm{B}}\right\}$. When $w^{\mathrm{A}}\left(w^{\mathrm{B}}\right)^{-1}>(<) \tilde{w}$, the price competitiveness of economy B (economy A) improves. According to Rodrik (2011, p. 192), "[d]ifferences in productivity account for between 80 to 90 percent of the variation in wages around the world.". Finally, for estimations of the levels and trends in the capital profitability across the world (1995-2007), see Chou et al. (2016). 
be correlated with the implementation of economic policies seeking to promote exports through income redistribution from wage incomes, with low propensities to save, to profit incomes, with high propensities to save (Kiefer and Rada, 2015). At the same time, empirical evidence from the ten largest countries (in terms of their share of world GDP) suggests that, due to a "global saving glut", the world interest rate is currently low, relatively to the world growth rate, and this explains the new stylized fact that the current account and the trade balances are positively correlated during the second globalization (while they were negatively correlated during the "first globalization", 1870s-1910s (Eugeni, 2016)). Although important, these mechanisms lie, however, outside the domain of our model.

\section{Conclusion}

We have used a Goodwin-type model, in order to study empirically the US economy in the time period 1960-2012. In comparison to other contributions, the present work uses the Bhaduri-Marglin accumulation function, presents formally some useful mathematical results and econometrically estimates the proposed model, using Bayesian techniques. Meanwhile, the simplifying assumptions of a constant capitalpotential output ratio and of a given and constant fraction of profits saved are relaxed, a choice which proves to be empirically justified and improves significantly the performance of our proposed model. Also, the total period is broken down into subperiods based on the relevant structural break tests conducted.

Undoubtedly, future and more extended research on the subject seems to be necessary focusing on additional factors, which have often proved to be relevant, namely technological change, wage savings, monetary and fiscal policies, 'overhead' labour and capital heterogeneity. On the other hand, the proposed approach should be extended to include international linkages between goods and asset markets that could help further explain global imbalances. We think that both ideas are of great interest and constitute good examples for future work in the field. 


\section{References}

Amadeo, E. J. (1986), "The role of capacity utilization in long-period analysis," Political Economy, 2 (2), pp. 147-185.

Andronov, A. A., Vitt, A. A. and Khaikin, S. E. (1987), Theory of Oscillators, Dover, New York.

Barbosa-Filho, N. (2015), "Elasticity of substitution and social conflict: a structuralist note on Piketty's Capital in the Twenty-First Century," Cambridge Journal of Economics, Vol. 40 (4), pp.1167-1183.

Barbosa-Filho, N. H. and Taylor, L. (2006), "Distributive and demand cycles in the U.S. economy - a structuralist Goodwin model," Metroeconomica, 57 (3), pp. 389-411.

Barrales, J. and von Arnim, R. (2017), "Longer-run distributive cycles: wavelet decompositions for the US, 1948-2011," Review of Keynesian Economics, Vol. 5 (2), pp. 196-217.

Bhaduri, A. (2008), "On the dynamics of profit-led and wage-led growth," Cambridge Journal of Economics, Vol. 32 (1), pp. 147-160.

Bhaduri, A. and Marglin, S. (1990), "Unemployment and the real wage rate: the economic basis for contesting political ideologies," Cambridge Journal of Economics, Vol. 14 (4), pp. 375-393.

Blecker, R.A. (1989), "International competition, income distribution and economic growth," Cambridge Journal of Economics, Vol. 13 (3), pp. 395-412.

Blecker, R.A. (2016), "Wage-led versus profit-led demand regimes: the long and the short of it," Review of Keynesian Economics, Vol. 4 (4), pp. 373-390.

Bowles, S. and Boyer, R. (1988), "Labor discipline and aggregate demand: A macroeconomic model," American Economic Review, Vol. 78 (2), pp. 395-400.

Canry, N. (2005), "Wage-led regime, profit-led regime and cycles: a model," Économie Appliquée, Vol. 58 (1), pp. 143-163.

Chopin, N. (2002), “A sequential particle filter method for static models," Biometrika, Vol. 89 (3), pp. 539-551.

Chopin, N. (2004), "Central limit theorem for sequential Monte Carlo methods and its application to Bayesian inference," Annals of Statistics, Vol. 32 (6), pp. 2385-2411.

Chou, N.-T., Izyumov, A. and Vahaly, J. (2016) "Rates of return on capital across the world: are they converging?," Cambridge Journal of Economics, Vol. 40 (4), pp. 1149-1166.

David, P.A. (1991), Computer and dynamo: The modern productivity paradox in a not-toodistant mirror, in OECD, Technology and Productivity. The Challenge for Economic Policy, OECD, Paris.

Durham, G. and Geweke, J. (2014), "Adaptive sequential posterior simulators for massively parallel computing environments," Advances in Econometrics, Vol. 34, pp. 1-44.

Dutt, A.K. (1990) Growth, Distribution and Uneven Development, Cambridge, Cambridge University Press.

Eugeni, S. (2016), "Global imbalances in the XIX, XX and the XXI centuries," Economics Letters, Vol. 145, pp. 69-72.

Flaschel, P. and Luchtenberg, S. (2012), Roads to Social Capitalism. Theory, Evidence and Policy, Edward Elgar, Cheltenham.

Flaschel, P., Groh, G., Kauermann, G. and Teuber, T. (2009), "The classical growth cycle after fifteen years of new observations," in P. Flaschel and M. Landesmann (eds.): Mathematical Economics and the Dynamics of Capitalism, Routledge, London. 
Foley, D.K. (2003), "Endogenous technical change with externalities in a classical growth model," Journal of Economic Behavior and Organization, Vol. 52 (2), pp.167-189.

Freeman, C. (1987), "Information technology and the change in techno-economic paradigm," in C. Freeman and L. Soete (Eds), Technical Change and Full Employment, Basil Blackwell, Oxford.

Gilks, W.R. and Berzuini, C. (2001), "Following a moving target: Monte Carlo inference for dynamic Bayesian models," Journal of the Royal Statistical Society B, Vol. 63 (1), pp. 127-146.

Goldstein, J.P. (1996), "The empirical relevance of the cyclical profit squeeze: a reassertion," Review of Radical Political Economics, Vol. 28 (4), pp. 55-92.

Goodwin, R.M. (1967), “A growth cycle,” in C.H. Feinstein (ed.): Socialism, Capitalism and Economic Growth: Essays Presented to Maurice Dobb, Cambridge University Press, London

Goodwin, R.M. (1986), "Swinging along the turnpike with von Neumann and Sraffa," Cambridge Journal of Economics, Vol. 10 (3), pp. 203-210.

Goodwin, R.M. and Punzo, L.F. (1987), The Dynamics of a Capitalist Economy: A MultiSectoral Approach, Polity Press, Cambridge.

Gordon, D.M. (1995), "Growth, distribution, and the rules of the game: social structuralist macro foundations for a democratic economic policy," in G.A. Epstein and H.A. Gintis (eds): Macroeconomic Policy after the Conservative Era, Cambridge University Press, Cambridge.

Julius, A.J. (2005), "Steady-state growth and distribution with an endogenous direction of technical change," Metroeconomica, Vol. 56 (1), pp. 101-125.

Kiefer, D. and Rada, C. (2015), "Profit maximising goes global: The race to the bottom," Cambridge Journal of Economics, Vol. 39 (5), pp. 1333-1350.

Kurz, H.D. (1990), "Technical change, growth and distribution: A steady-state approach to 'unsteady' growth," in H.D. Kurz: Capital, Distribution and Effective Demand. Studies in the 'Classical' Approach to Economic Theory, Polity Press, Cambridge.

Kurz, H. D. (1994), "Growth and distribution," Review of Political Economy, Vol. 6 (4), pp. 393-420.

Lavoie, M. (1995), "The Kaleckian model of growth and distribution and its neo-Ricardian and neo-Marxian critiques," Cambridge Journal of Economics, Vol. 19 (6), pp.789818.

Lorenz, H.-W. (1989), Nonlinear Dynamical Economics and Chaotic Motion, SpringerVerlag, Berlin.

Marglin, S.A. and Bhaduri, A. (1988), "Profit squeeze and Keynesian theory," World Institute for Development Economics Research of the United Nations University, Working Paper 39, April 1988.

Mariolis, T. (2013), "Goodwin's growth cycle model with the Bhaduri-Marglin accumulation function," Evolutionary and Institutional Economics Review, Vol. 10 (1), pp. 131-144.

Mohun, S. (2009), "Aggregate capital productivity in the US economy, 1964-2001," Cambridge Journal of Economics, Vol. 33 (5), pp. 1023-1046.

Nikiforos, M. and Foley, D.K. (2012), "Distribution and capacity utilization: conceptual issues and empirical evidence," Metroeconomica, Vol. 63 (1), pp. 200-229.

Rodousakis, N. (2014), "The stability properties of Goodwin's growth cycle model with a variable elasticity of substitution production function," Studies in Microeconomics, Vol. 2 (2), pp. 213-223. 
Rodousakis, N. (2015), "Goodwin's growth cycle model with the Bhaduri-Marglin accumulation function: a note on the C.E.S. case," Evolutionary and Institutional Economics Review, Vol. 12 (1), pp. 105-114.

Rodrik, D. (2011), The Globalization Paradox. Why global market, states and democracy can't coexist, Oxford University Press, Oxford.

Rowthorn, B. (1981), "Demand, real wages and economic growth," Thames Papers in Political Economy, Autumn, pp. 1-39.

Samuelson, P.A. (1971), "Generalized predator-prey oscillations in ecological and economic equilibrium," Proceedings of the National Academy of Sciences USA, Vol. 68 (5), pp. 980-983.

Sasaki, H. (2013), "Cyclical growth in a Goodwin-Kalecki-Marx model," Journal of Economics, Vol. 108 (2), pp. 145-171.

Shah, A. and Desai, M. (1981), "Growth cycles with induced technical change," The Economic Journal, Vol. 91 (364), pp. 1006-1010.

Skott, P. (2012), "Shortcomings of the Kaleckian investment function," Metroeconomica, Vol. 63 (1), pp. 109-138.

Skov A.M. (2004), Oil and Gas Energy in US Economy, SPE Annual Technical Conference and Exhibition, 26-29 September, Houston, Texas. https://doi.org/10.2118/90184-MS

Sportelli, M.C. (1995), "A Kolmogoroff generalized predator-prey model of Goodwin's growth cycle," Journal of Economics, Vol. 61 (1), pp. 35-64.

Stockhammer, E. and Michell, J. (2017), "Pseudo-Goodwin cycles in a Minsky Model," Cambridge Journal of Economics, Vol. 41 (1), pp. 105-125.

Tavani, D. (2012), "Wage bargaining and induced technical change in a linear economy: Model and application to the US (1963-2003)," Structural Change and Economic Dynamics, Vol. 23 (2), pp.117-126.

Tavani, D. (2013), "Bargaining over productivity and wages when technical change is induced: implications for growth, distribution, and employment," Journal of Economics, Vol. 109 (3), pp. 207-244.

Tavani, D., Flaschel, P. and Taylor, L. (2011), "Estimated non-linearities and multiple equilibria in a model of distributive-demand cycles," International Review of Applied Economics, Vol. 25 (5), pp. 519-538.

Tavani, D. and Zamparelli, L. (2015), "Endogenous technical change, employment and distribution in the Goodwin model of the growth cycle," Studies in Nonlinear Dynamics and Econometrics, Vol. 19 (2), pp. 209-226.

Tavani, D. and Zamparelli, L. (2017), "Endogenous technical change in alternative theories of growth and distribution," Journal of Economic Surveys, Vol. 31 (5), pp.1272-1303.

Veneziani, R. and Mohun, S. (2006), "Structural stability and Goodwin's growth cycle," Structural Change and Economic Dynamics, Vol. 17 (4), pp. 437-451.

Vercelli, A. (1984), "Fluctuations and growth: Keynes, Schumpeter, Marx and the structural instability of capitalism," in Goodwin, R M., Krüger, M. and Vercelli, A. (eds): Nonlinear Models of Fluctuating Growth, Springer, Berlin.

van der Ploeg, F. (1987), "Growth cycles, induced technical change, and perpetual conflict over the distribution of income," Journal of Macroeconomics, Vol. 9 (1), pp. 1-12.

von Arnim, R., Tavani, D. and Carvalho, L. (2014), "Redistribution in a Neo-Kaleckian Twocountry Model," Metroeconomica, Vol. 65 (3), pp. 430-459.

von Arnim, R. and Barrales, J. (2015), "Demand-driven Goodwin cycles with Kaldorian and Kaleckian features," Review of Keynesian Economics, Vol. 3 (3), pp. 351-373. 
Wolff E.N. (2006), "The growth of information workers in the US economy, 1950-2000: The role of technological change, computerization, and structural change," Economic Systems Research, Vol. 18 (3), pp. 221-255.

Wolff, E.N. (2003), "What's behind the rise in profitability in the us in the 1980's and in the 1990's?," Cambridge Journal of Economics, Vol. 27 (4), pp. 479-499.

Zamparelli, L. (2015), "Induced innovation, endogenous technical change and income distribution in a labor constrained model of classical growth," Metroeconomica, Vol. 66 (2), pp. 243-262.

\section{TECHNICAL APPENDIX: SEQUENTIAL MONTE CARLO}

Chopin (2002) proposed a sequential PF for static models. Given a target posterior $p(\theta \mid Y):=p\left(\theta \mid Y_{1: T}\right)$, a particle system is a sequence $\left\{\theta_{j}, w_{j}\right\}$ such that $E(h(\theta) \mid Y):=\int h(\theta) p(\theta \mid Y) d \theta \cong \lim _{J \rightarrow \infty} \frac{\sum_{j=1}^{J} w_{j} h\left(\theta_{j}\right)}{\sum_{j=1}^{J} w_{j}}$, almost surely, for any measurable function $h$, provided the expectation exists. We consider the sequence of posterior distributions $p_{t}:=p\left(\theta \mid Y_{t}\right)$. The PF algorithm is as follows:

Step 1. Reweight: update the weights $w_{j} \leftarrow w_{j} \frac{p_{t+1}\left(\theta_{j}\right)}{p_{t}\left(\theta_{j}\right)}, j=1, \ldots, J$.

Step 2: Resampling: resample $\left\{\theta_{j}, w_{j} J_{j=1}^{H} \rightarrow\left\{\theta_{j}^{r}, 1\right\}_{j=1}^{J}\right\}$

Step 3. Move: draw $\theta_{j}^{m} \sim K_{t+1}\left(\theta_{j}^{r}\right), j=1, \ldots, J$, where $K_{t+1}$ is any transition kernel whose stationary distribution is $p_{t+1}$.

Step 4. Loop: $t \leftarrow t+1,\left\{\theta_{j}, w_{j}\right\}_{j=1}^{J} \leftarrow\left\{\theta_{j}^{m}, 1\right\}_{j=1}^{J}$ and return to Step 1 .

Chopin (2002) recommends the independence Metropolis algorithm to select the kernel, which requires a source distribution. A possible choice, if we sampled from $p_{n}(n<T)$, with respect to $p_{n+s}$ is $N\left(\hat{E}_{n+s}, \hat{V}_{n+s}\right)$ where

$$
\hat{E}_{n+s}=\frac{\sum_{j=1}^{J} w_{j} \theta_{j}}{\sum_{j=1}^{J} w_{j}}, \hat{V}_{n+s}=\frac{\sum_{j=1}^{J} w_{j}\left(\theta_{j}-E_{n+p}\right)\left(\theta_{j}-E_{n+p}\right)}{\sum_{j=1}^{J} w_{j}} .
$$

The strategy can be parallelized easily. If $K$ processors are available, we can partition the particle system into $K$ subsets, say $\left.S_{k}, k=1, \ldots, K\right)$, and implement computations for particles of $S_{k}$ in processor $k$. The algorithm can deal with new data at a nearly geometric rate and, therefore, the frequency of exchanging information between processors (after reweighting) decreases at a rate exponential to $n$, which is highly efficient. 
Resampling, according to $\theta_{j}^{m} \sim K_{t}\left(\theta_{j}^{r},.\right)$, reduces particle degeneracy (Gilks and Berzuini, 2001) since identical replicates of a single particle are replaced by new ones, without altering the stationary distribution. For this application, using $J=2^{12}$ particles gave a mean squared error in posterior means of $10^{-5}$ over 100 runs.

Chopin (2004) introduces a variation of MSC in which the observation dates at which each cycle terminates (say $t_{1}, \ldots, t_{L}$ ) and the parameters involved in specifying the Metropolis updates ( say $\lambda_{1}, \ldots, \lambda_{L}$ ) are specified. Therefore, $0=t_{0}<t_{1}<\ldots<t_{L}=T$ and we have the following scheme (we rely heavily on Durham and Geweke, 2014).

Step 1. Initialize $l=0$ and $\theta_{j n}^{(l)} \sim p(\theta), j \in J, n \in N$.

Step 2. For $l=1, \ldots, L$ :

(a) Correction phase:

(i) $w_{j n}\left(t_{l-1}\right)=1, j \in J, n \in N$

(ii) For $s=t_{l-1}+1, \ldots, t_{l}$

$$
w_{j n}(s)=w_{j n}(s-1) p\left(y_{s} \mid y_{1: s-1}, \theta_{j n}^{(l-1)}\right), j \in J, n \in N .
$$

(iii) $w_{j n}^{(l-1)}:=w_{j n}\left(t_{l}\right), j \in J, n \in N$.

(b) Selection phase, applied independently to each group $j \in J$ : Using multinomial or residual sampling based on $\left\{w_{j n}^{(l)}, n \in N\right\}$, select

$$
\left\{\theta_{j n}^{(l, 0)}, n \in N\right\}
$$

from $\left\{\theta_{j n}^{(l-1)}, n \in N\right\}$.

(c) Mutation phase, applied independently across $j \in J, n \in N$ :

$$
\theta_{j n}^{(l)} \sim p\left(\theta \mid y_{1: t}, \theta_{j n}^{(0)}, \lambda_{l}\right)
$$

where the drawings are independent and the pdf above satisfies the invariance condition:

$$
\int_{\Theta} p\left(\theta \mid y_{1: t_{l}}, \theta^{*}, \lambda_{l}\right) p\left(\theta^{*} \mid y_{1::_{l}}\right) d v\left(\theta^{*}\right)=p\left(\theta \mid y_{1::_{l}}\right) .
$$


Step 3. $\theta_{j n}:=\theta_{j n}^{(l)}, j \in J, n \in N$.

At the end of every cycle, the particles $\theta_{j n}^{(l)}$ have the same distribution $p\left(\theta \mid y_{1: t}\right)$. The amount of dependence, within each group, depends upon the success of the Mutation phase, which avoids degeneracy.

Table 0. Estimated IS - curves

\begin{tabular}{|c|c|c|}
\hline Model Specification & BIC & AIC \\
\hline Linear & -282.19 & -286.96 \\
\hline Quadratic & -279.14 & -284.88 \\
\hline Exponential & -280.15 & -284.77 \\
\hline Polynomial & -277.82 & -285.47 \\
\hline Logistic & -278.87 & -282.45 \\
\hline
\end{tabular}


Table 1. Estimated model parameters by period

\begin{tabular}{|l|c|c|c|c|c|c|}
\hline Period & $\overline{e_{1}}$ & $\overline{e_{2}}$ & $\theta$ & $z$ & $\gamma$ & $\delta$ \\
\hline & -2.53 & 1.22 & 0.12 & -2.35 & 0.043 & 0.032 \\
$\mathbf{1 9 6 0 - 1 9 7 3}$ & $(0.44)$ & $(0.32)$ & $(0.021)$ & $(0.44)$ & $(0.007)$ & $(0.005)$ \\
\hline & -15.76 & -2.14 & 0.21 & -2.40 & 0.057 & 0.021 \\
$\mathbf{1 9 7 4 - 1 9 7 8}$ & $(3.44)$ & $(0.44)$ & $(0.025)$ & $(0.13)$ & $(0.012)$ & $(0.004)$ \\
\hline & -2.67 & 1.19 & -0.05 & 1.15 & 0.081 & 0.044 \\
$\mathbf{1 9 7 9 - 2 0 0 6}$ & $(0.47)$ & $(0.23)$ & $(0.0134)$ & $(0.32)$ & $(0.035)$ & $(0.003)$ \\
\hline & -6.92 & 1.23 & -0.06 & 2.54 & 0.053 & 0.013 \\
$\mathbf{2 0 0 7 - 2 0 1 2}$ & $(1.23)$ & $(0.35)$ & $(0.024)$ & $(0.40)$ & $(0.022)$ & $(0.005)$ \\
\hline
\end{tabular}

Note: Posterior means and posterior standard deviations in parentheses. 
Figure 1. Marginal posterior density of $e_{1}$

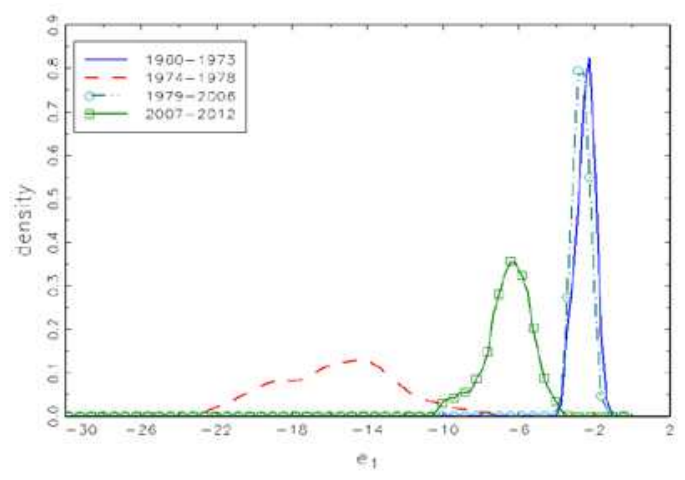

Figure 3. Marginal posterior density of $\theta$

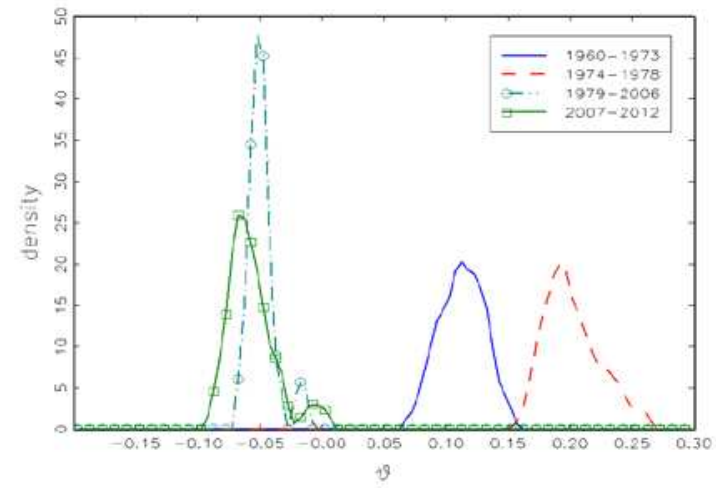

Figure 5. Marginal posterior density of $\gamma$
Figure 2. Marginal posterior density of $e_{2}$

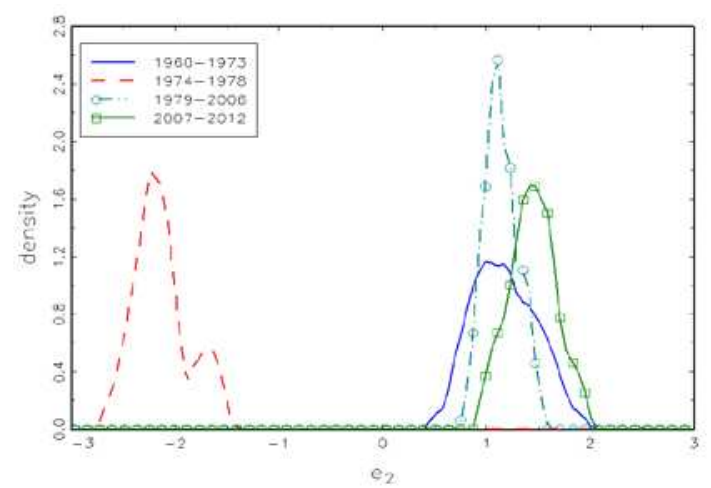

Figure 4. Marginal posterior density of $z$

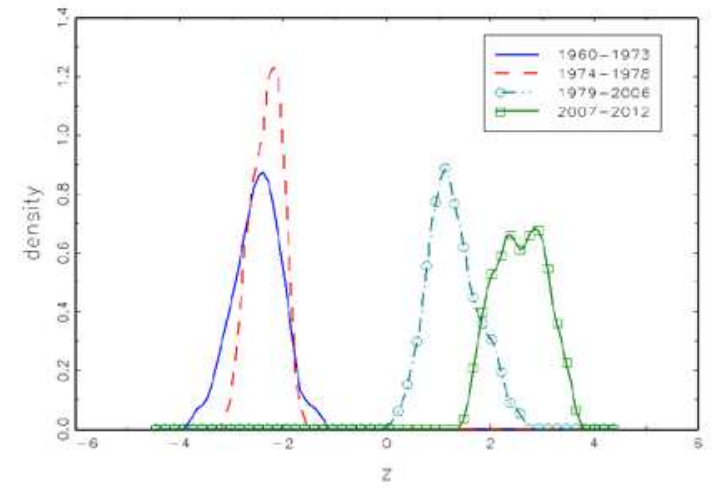

Figure 6. Marginal posterior density of $\delta$ 

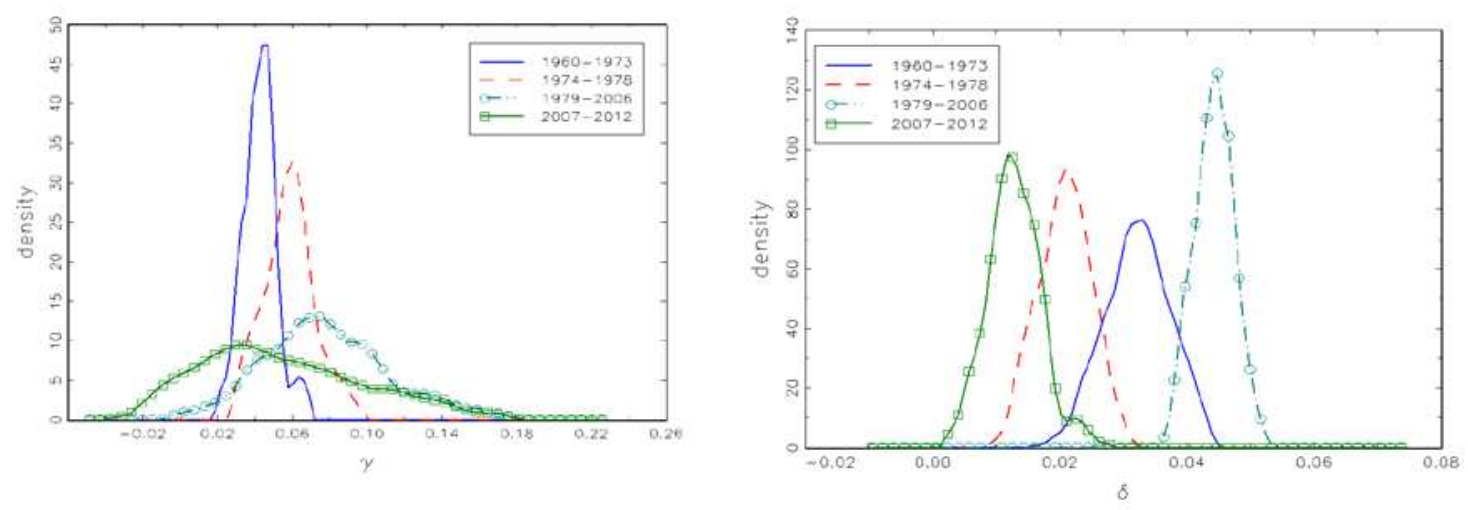

Table 2. Regimes and stability of each period

\begin{tabular}{|c|c|c|c|c|c|}
\hline Period & $\overline{e_{2}}$ & $\operatorname{Tr} \mathbf{J}^{* *}$ & Det $\mathbf{J}^{* *}$ & Stability & Regime \\
\hline $\mathbf{1 9 6 0 - 1 9 7 3}$ & 1.22 & $<0$ & $>0$ & Locally Stable & Exhilarationist \\
\hline $\mathbf{1 9 7 4 - 1 9 7 8}$ & -2.14 & $>0$ & $<0$ & Saddle Point & Underconsumption \\
\hline $\mathbf{1 9 7 9 - 2 0 0 6}$ & 1.19 & $<0$ & $>0$ & Locally Stable & Exhilarationist \\
\hline $\mathbf{2 0 0 7 - 2 0 1 2}$ & 1.23 & $<0$ & $>0$ & Locally Stable & Exhilarationist \\
\hline
\end{tabular}

